Key Words:

Process analysis, chemometrics

Retention:

Permanent

\title{
RECALIBRATION OF H CANYON ONLINE SPECTROPHOTOMETER AT EXTENDED URANIUM CONCENTRATION
}

Robert J. Lascola

OCTOBER, 2008

Savannah River National Laboratory

Savannah River Nuclear Solutions

Aiken, SC 29808

Prepared for the U.S. Department of Energy Under

Contract Number DE-AC09-08SR22470 


\section{DISCLAIMER}

This work was prepared under an agreement with and funded by the U.S. Government. Neither the U. S. Government or its employees, nor any of its contractors, subcontractors or their employees, makes any express or implied:

1. warranty or assumes any legal liability for the accuracy, completeness, or for the use or results of such use of any information, product, or process disclosed; or

2. representation that such use or results of such use would not infringe privately owned rights; or

3. endorsement or recommendation of any specifically identified commercial product, process, or service.

Any views and opinions of authors expressed in this work do not necessarily state or reflect those of the United States Government, or its contractors, or subcontractors.

Printed in the United States of America

Prepared for

U.S. Department of Energy 
Key Words:

Process analysis, chemometrics

Retention:

Permanent

\title{
RECALIBRATION OF H CANYON ONLINE SPECTROPHOTOMETER AT EXTENDED URANIUM CONCENTRATION
}

\author{
Robert J. Lascola
}

OCTOBER, 2008

Savannah River National Laboratory

Savannah River Nuclear Solutions

Savannah River Site

Aiken, SC 29808 
SRNL-STI-2008-00411, REV. 0

\section{REVIEWS AND APPROVALS}

R.J. Lascola, Spectroscopy and Separations Group, SRNL/AD

Date

K.E. Zeigler, Spectroscopy and Separations Group, SRNL/AD (Technical Review) Date

M.J. Barnes, Manager, Spectroscopy and Separations Group, SRNL/AD

Date

R.A. Eubanks, Engineer, HMD/H Canyon Engineering

Date

P.M. Palmer, Manager, HMD/H Canyon Engineering

Date

- ii - 


\section{TABLE OF CONTENTS}

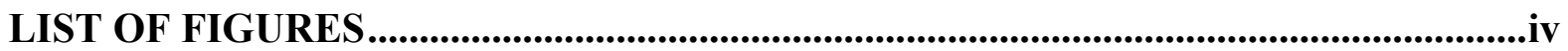

LIST OF TABLES............................................................................................................................iv

LIST OF ACRONYMS ..........................................................................................................

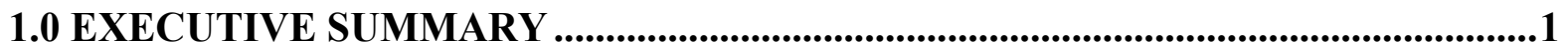

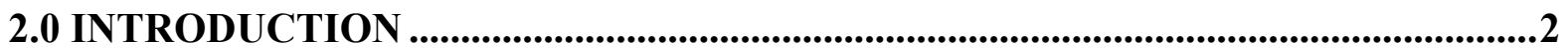

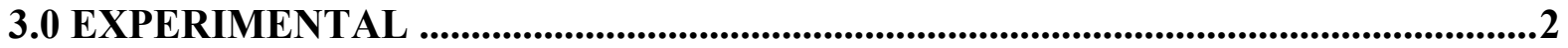

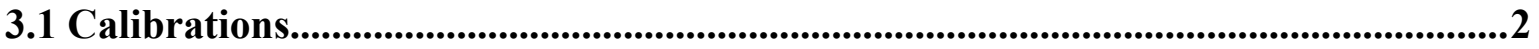

3.1.1 Solutions...........................................................................................................................2

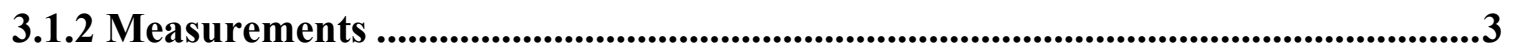

3.1.3 Analysis ..........................................................................................................3

3.2 Hardware ............................................................................................................................

3.2.1 Flow Cells.....................................................................................................................

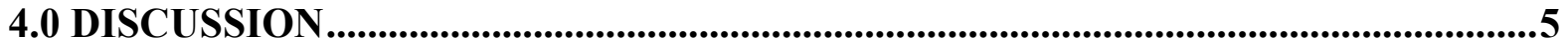

4.1 Analysis Scheme …………………........................................................................................5

4.1.1 Uranium ..................................................................................................................................6

4.1.2 Nitric Acid .................................................................................................................

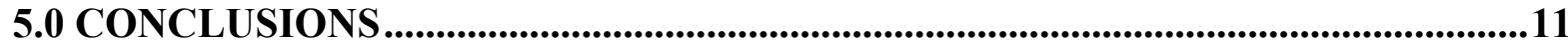

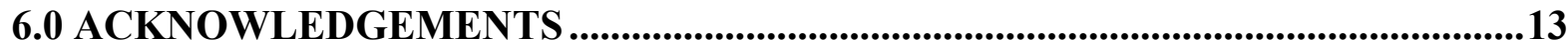

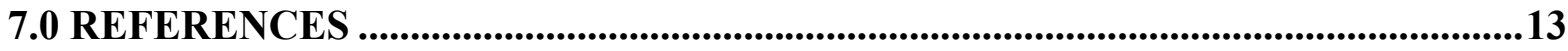

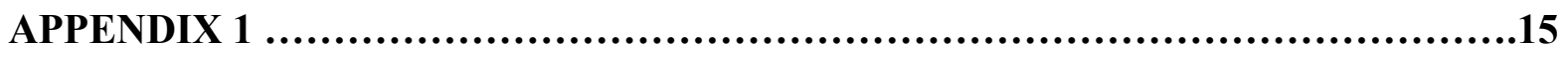




\section{LIST OF FIGURES}

Figure 1. Concentration matrix for calibrations. ........................................................

Figure 2. Spectrophotometer flow cell. .....................................................................4

Figure 3. Prediction residuals for uranium model. ..........................................................9

Figure 4. Prediction residuals for nitrate model. ........................................................... 12

\section{LIST OF TABLES}

Table 1. Uranium model: GA comparison ............................................................... 6

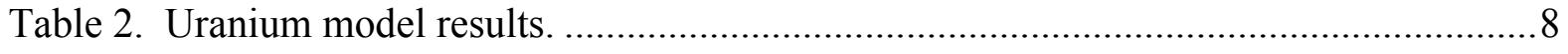

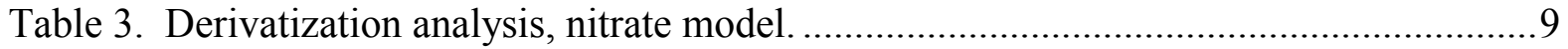

Table 4. Nitrate model: GA comparison. ............................................................... 10

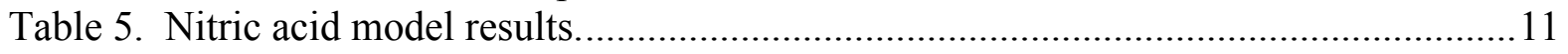

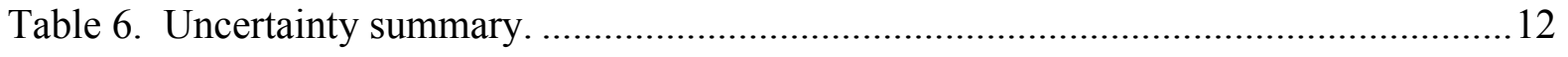




\section{LIST OF ACRONYMS}

$\begin{array}{ll}\text { AD } & \text { Analytical Development } \\ \text { GA } & \text { Genetic algorithm } \\ \text { LOQ } & \text { Limit of quantitation } \\ \mathrm{NO}_{3} & \text { Nitric acid } \\ \text { PC } & \text { Principal component } \\ \text { PLS } & \text { Partial least-squares } \\ \text { RMSECV } & \text { Root-mean square error of cross-validation } \\ \text { SEP } & \text { Standard error of prediction } \\ \text { SRNL } & \text { Savannah River National Laboratory } \\ \text { SRS } & \text { Savannah River Site } \\ \text { U } & \text { Uranium } \\ \text { UV } & \text { Ultraviolet }\end{array}$




\subsection{EXECUTIVE SUMMARY}

The online spectrophotometers in H Canyon Second Uranium Cycle were modified to allow measurement of uranium and nitric acid for the Super Kukla processing campaign. The expected uranium concentrations, which are higher than those that have been recently processed, required new flow cells with one-third the optical path length of the existing cells. Also, new uranium and nitric acid calibrations were made. The estimated reading uncertainties $(2 \sigma)$ for Tanks 15.4 and 17.5 are $\sim 5 \%$ for uranium and $\sim 25 \%$ for nitric acid. 


\subsection{INTRODUCTION}

The H Canyon online spectrophotometers are calibrated for measurement of the uranium and nitric acid concentrations of several tanks in the $2^{\text {nd }}$ Uranium Cycle.[1] The spectrometers, flow cells, and prediction models are currently optimized for a process in which uranium concentrations are expected to range from $0-15 \mathrm{~g} / \mathrm{L}$ and nitric acid concentrations from $0.05-$ $6 \mathrm{M}$. However, an upcoming processing campaign will involve "Super Kukla" material, which has a lower than usual enrichment of fissionable uranium. Total uranium concentrations will be higher, spanning approximately 0-30 g/L U, with no change in the nitric acid concentrations. The new processing conditions require the installation of new flow cells with shorter path lengths. As the process solutions have a higher uranium concentration, the shorter path length is required to decrease the absorptivity to values closer to the optimal range for the instrument. Also, new uranium and nitric acid prediction models are required to span the extended uranium concentration range. The models will be developed for the 17.5 and 15.4 tanks, for which nitric acid concentrations will not exceed 1 M. The restricted acid range compared to the original models is anticipated to reduce the measurement uncertainty for both uranium and nitric acid.

\subsection{EXPERIMENTAL}

\subsection{CALIBRATIONS}

\subsubsection{Solutions}

Standard solutions were fabricated in SRNL by gravimetric addition of uranium and nitric acid stock solutions and water. Uranium stock solution was obtained from $\mathrm{H}$ Canyon from solution originally made by SRNL and characterized by Analytical Laboratories. Nitric acid solution was fabricated and characterized in SRNL. ${ }^{*}$ General laboratory equipment is maintained in AD's Measurement Systems and Equipment (MS\&E) program. Figure 1 provides the calibration matrix for the test solutions. Standard solutions were divided into a calibration and validation set. Spectra of the calibration solutions were used to build the prediction models, while spectra of the validation solutions were used as independent checks of model performance. Solutions used for model calibration are marked by dots $(\bullet)$. The concentrations of these solutions are distributed in a pattern across the expected processing range, with minor variations arising during mixing. Validation solutions, marked by crosses $(\mathrm{x})$, are evenly distributed. Uranium and acid concentrations within each set are minimally correlated $(r(\mathrm{cal})=0.0002, r(\mathrm{val})=0.04)$. Concentrations in the calibration set span those in the validation set. The calibration set also spans the expected process concentrations. ${ }^{\dagger}$

\footnotetext{
* Uranium stock solution: $[\mathrm{U}]=437 \mathrm{~g} / \mathrm{L}(\sigma=0.82 \%),\left[\mathrm{HNO}_{3}\right]=0.24 \mathrm{M}(\sigma=3 \%)$. Nitric acid stock solution: $\left[\mathrm{HNO}_{3}\right]=6.7 \mathrm{M}(\sigma=10 \%)$. Instrument uncertainties for SRNL measurements: $\sigma_{\text {mass }}=0.002 \mathrm{~g}, \sigma_{\text {density }}=1 \%$. Uranium (both tanks): 0-30 g/L. Nitric acid: Tank 15.4, 0.05-0.25 M; Tank 17.5, 0.1-0.7 M.
} 


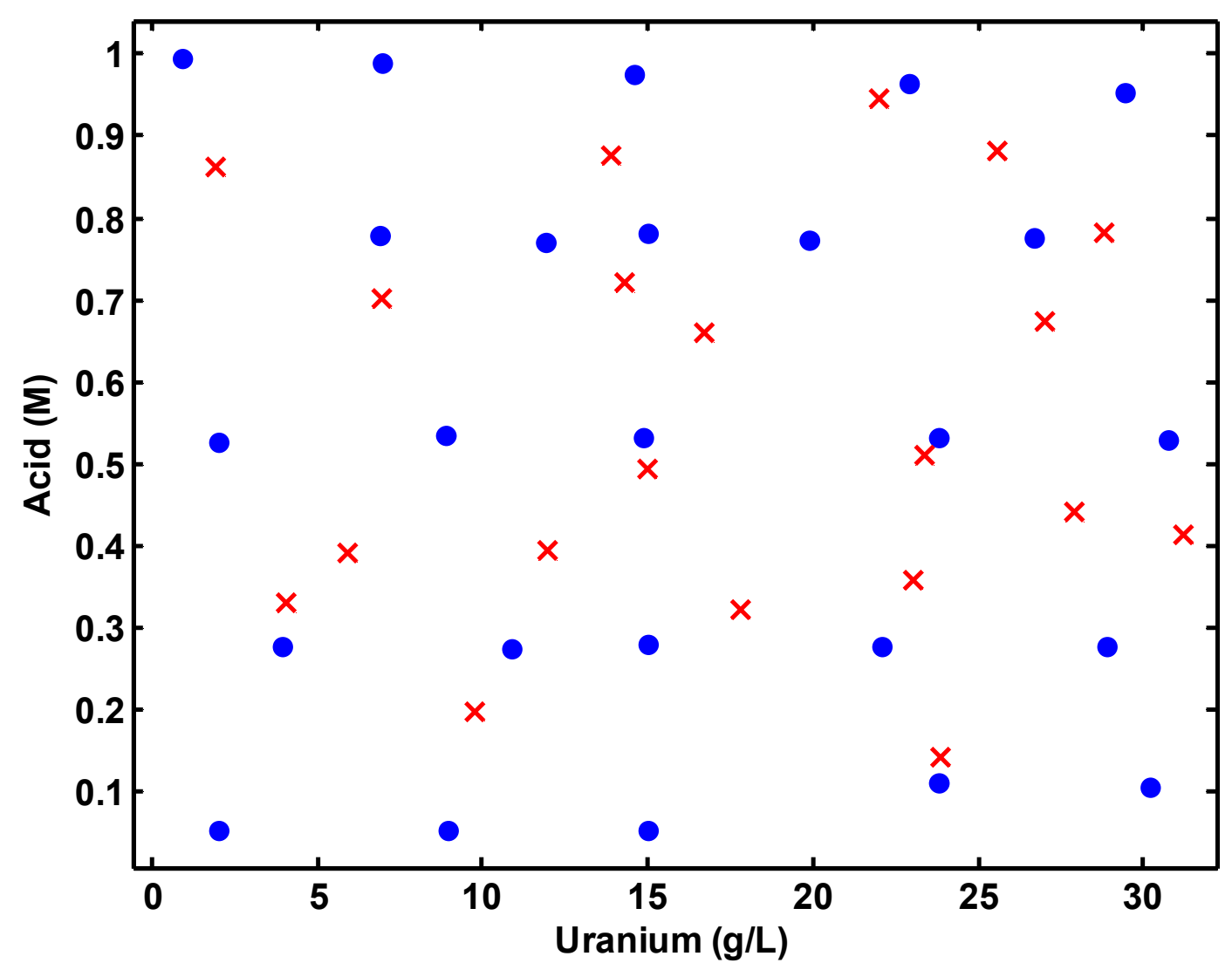

Figure 1. Concentration matrix for calibrations.

$$
(\bullet=\text { calibration, } \mathrm{x}=\text { validation })
$$

\subsubsection{Measurements}

Absorption spectra of the calibration and validation solutions and distilled water blanks were measured using the $\mathrm{H}$ Canyon spectrophotometers. Solutions were measured in random order using the "standard channel" (multiplexer Channel 2), which accesses a cuvette holder located in the Warm Sample Aisle. A new "zero file", to account for light throughput differences compared to the reference channel, was recorded. Each solution was contained in a $1 \mathrm{~cm}$ disposable capped plastic cuvette. At least three consecutive spectra were obtained for each solution ( $0.15 \mathrm{~s}$ integration time, 100x averaging). One solution ("cal04", $23.8 \mathrm{~g} / \mathrm{L}$ $\mathrm{U}, 0.111 \mathrm{M}$ acid) was measured three times, at the beginning, middle, and end of the set, to accommodate any time-dependent changes. Spectra were recorded from $300-700 \mathrm{~nm}$. Spectra were recorded automatically every 30 seconds.

\subsubsection{Analysis}

Absorbance spectra were divided into calibration and validation sets. Obviously incorrect spectra (no cuvette present, or cuvette inserted during a data acquisition cycle) were deleted. Preliminary analysis of the data with partial least-squares (PLS) analysis was done with Solo (version 4.0, Eigenvector Research, Inc., Wenatchee, WA). Data analysis at this stage included outlier detection, wavelength selection, and optimization of spectral preprocessing 
(such as derivatization). Final prediction models were created with MVASRS (version 1.5.10, Savannah River Technology Center). MVASRS produces model files that are compatible with the data acquisition software.

\subsection{HARDWARE}

\subsubsection{Flow Cells}

The new flow cells have the same basic design as the original flow cells. A schematic diagram of the flow cell is shown in Figure 2. The optical cell is based on a standard compression-fitting " $T$ " where the solution enters and exits through the middle stem and light is propagated through the facing ends. The optical path length is defined by the distance between two collimating lenses inserted into the facing ends (denoted by the grey cylinders). In the unmodified "T", internal shoulders define the path length to be 1 inch. If a shorter path length is required, the shoulders must be drilled out.

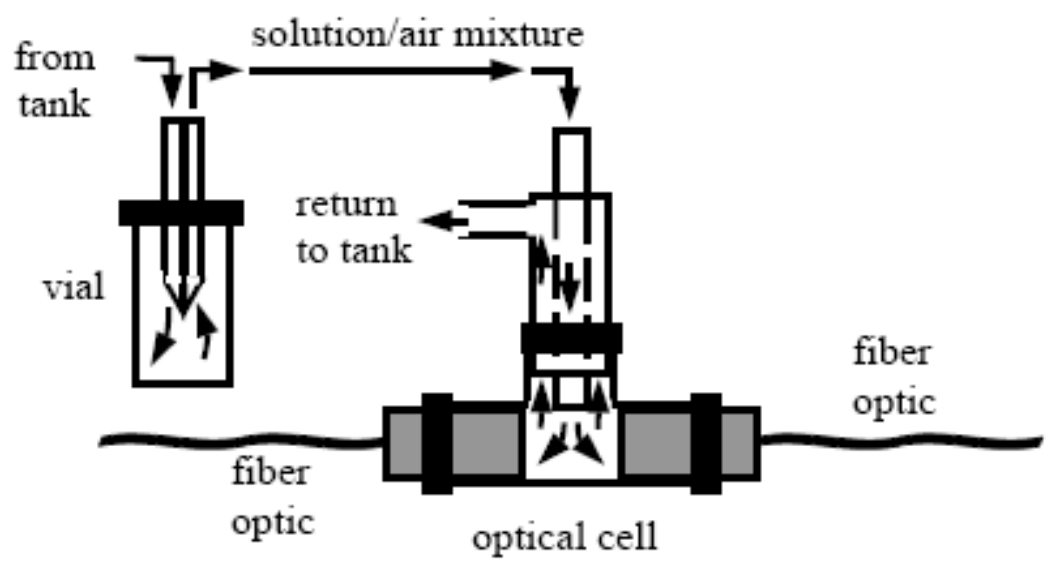

Figure 2. Spectrophotometer flow cell.

The upper limit of the uranium concentration range is expected to increase nearly three-fold for the Super Kukla campaign (from 11 to $30 \mathrm{~g} / \mathrm{L}$ ). In order to preserve the same spectral absorbance, the flow cell path length is required to decrease by the same factor, i.e. from 1 inch to 0.3 inches. The original collimating lenses were found to be too short to be inserted into the " $T$ " at the desired separation and still have effective seating of the sealing ferrule. Therefore, custom collimating lenses with an extended body length ( 0.375 " added to the normal 0.875") were ordered (part no. 43.1050, Equitech International, New Ellenton, SC). The collimating lenses are otherwise identical (316L stainless steel body, UV quartz lenses, internal Kalrez O-ring seal, stainless steel lock nuts for SMA fiber couplers). The "T"s are marked by the engraved labels "SK1", "SK2", and "SK3"."

\footnotetext{
* Actual path lengths must be determined by measurement of test solutions. Approximate path lengths are calculated as the difference between the end-to-end distance of the inserted lenses and the summed length of the individual lenses. All measurements are in inches. SK1: $3.1720-1.4395-1.4405=0.2920$. SK2: $3.1765-$ $1.4400-1.4400=0.2965$. SK3: $3.1830-1.4240-1.4415=0.3175$.
} 


\subsection{DISCUSSION}

\subsection{ANALYSIS SCHEME}

Preliminary analyses for both the uranium and nitric acid PLS prediction models were conducted to optimize spectral derivatization parameters and the models' spectral ranges. Previous development work has shown that using the second derivative of the spectrum reduces the effects of changes of measurement conditions on the spectrum. These changes may appear as a baseline offset due to variations in loading the flow cell, or as a slope in the baseline caused by impurities or fluctuations in the spectrometer lamp output. The derivatization also smooths the data, with the amount of smoothing determined by the order of the polynomial used to approximate the data and the width of the data window over which the polynomial is fit. As the derivatization can affect the data quality, it is reasonable to expect that the choice of parameters will influence the choice of spectral range.

The most straightforward choice for the spectral range is to include all wavelengths where the target analyte gives a signal. However, some responsive wavelengths may not correlate as well with analyte concentration as others, due to increased noise or response nonlinearities. Therefore, when developing a model, it is useful to test the results of changing the selection of the spectral range. For absorption spectroscopy, there may be several hundred response channels, and explicitly examining all the possible subsets of these is prohibitive. Automated techniques, such as genetic algorithms (GA) [2,3], simplify the selection. In the GA process, an initial population of sets is defined, each of which has a unique subset of the spectral range. Models are created for each member of the population. Those members which give the best models are combined in a predefined way to create a second-generation population, for which new models are developed. The process is repeated for a given number of generations, or until there is no discernible improvement in the models.

For both uranium and nitric acid models, the GA process was repeated for data that had been subjected to a variety of derivatizing options, to determine if there was an optimal derivatization scheme for this data set. Once the optimal processing conditions were chosen, a final model was generated.

The discussion of model uncertainty in this section assumes that there is no uncertainty associated with the reference concentrations. All comparisons of different preprocessing options and development of optimized prediction models are based on the same reference concentrations. If the reference errors are small and randomly distributed, there should be no correlation between them and the model errors. However, the reference errors must be included when determining the total method uncertainty, as will be done in Section 5. 


\subsubsection{Uranium}

Five derivatization schemes were tested using identical GA parameters ${ }^{*}$; evaluations were made based on the ability of the model to fit the data fed into it (e.g. no independent validation data was evaluated). The tests demonstrated that there is only a very weak dependence of the fitting results on the smoothing window and order of the fitting polynomial. For smoothing windows from 9 to 51 points, the fit error varied between 0.22 to $0.24 \mathrm{~g} / \mathrm{L}$ (polynomial order $=5^{\text {th }}$ ). For a given window size $(15$ points), there was no significant difference between $3^{\text {rd }}$ and $5^{\text {th }}$ order polynomials. Based on these results, a $5^{\text {th }}$ order polynomial with a 15-point window was used in subsequent work.

Next, wavelength selection was refined. The candidate wavelength range was truncated to $380-550 \mathrm{~nm}$. This step eliminated a high noise region, 300-380 nm, where lamp output is low, and a region where uranium does not absorb light, 550-700 nm. Two models were generated. One model incorporated all 208 points between $380-550 \mathrm{~nm}$. The other model was based on a GA analysis which started by allowing half the initial wavelength range (randomly selected) but had no limits on the final data inclusion. The data range was organized into 5-point blocks to streamline the selection process. The blocking is justified because the absorption features are broad and adjacent points are highly correlated in these spectra. The two models are compared in Table 1. In the table, PC (principal component) is the eigenvector resulting from PLS reduction of the data [4], \% X represents the amount of spectral variation that is reproduced, $\% \mathrm{Y}$ is the uranium concentration variation that is reproduced, RMSECV (root-mean square error of cross-validation) is a prediction error based on replication of the calibration set values ${ }^{\dagger}$, and "val. RMSE" is the prediction error for the validation data set, which was not used to make the model and thus is a more realistic estimate of future model performance.

Table 1. Uranium model: GA comparison

\begin{tabular}{|c|c|c|c|c|c|c|}
\hline & \multicolumn{3}{|c|}{ Full range } & \multicolumn{3}{c|}{ GA-selected range } \\
\hline \# points & \multicolumn{3}{|c|}{208} & \multicolumn{3}{c|}{61} \\
\hline \multirow{2}{*}{$\lambda$ included (nm) } & \multicolumn{3}{|c|}{$380-550$} & \multicolumn{3}{c|}{$384.2-388.3 ; 425.5-437.0 ; 454.3-$} \\
& \multicolumn{2}{|c|}{$\mathbf{3}$} & $\mathbf{1}$ & $\mathbf{2}$ & $\mathbf{3}$ \\
\hline PC & $\mathbf{1}$ & 0.10 & 0.00 & 99.86 & 0.14 & 0.00 \\
\hline \%X & 99.89 & 0.00 & 0.01 & 99.99 & 0.00 & 0.00 \\
\hline \%Y & 99.98 & 0.254 & 0.217 & 0.207 & 0.209 & 0.216 \\
\hline RMSECV (g/L) & 0.262 & 0.39 & 0.32 & 0.31 & - & ${ }^{-}$ \\
\hline $\begin{array}{c}\text { Val. RMSE } \\
\text { (g/L) }\end{array}$ & 0.42 & & & & & \\
\hline
\end{tabular}

(1) Not calculated.

\footnotetext{
* Population size: 96; window width: 5 (adjacent wavelength responses combined; feasible as the signal from adjacent wavelengths is highly correlated); initial wavelengths included: $25 \%$, target 10-50\%; max. generations: 20; mutation rate: 30\%; fitting details: partial least-squares (PLS), 2 latent vectors (LV), 5 contiguous splits for cross-validation, 1 iteration, data from 300-700 nm included.

${ }^{\dagger}$ A leave-one-out cross-validation was applied. In this scheme, a series of prediction models are made which sequentially exclude one of the samples. The models are then used to estimate the concentration of the excluded sample. The RMSECV is the overall prediction error of the excluded samples.
} 
For both models, the bulk of the variation is explained by the first PC. The general rule of thumb for systems with a linear response (for example, absorption spectra where Beer's Law is followed) is that there will be one PC for each factor that influences the data. For the range of uranium and nitric acid concentrations in this data set, uranium speciation is expected to be predominantly $\mathrm{UO}_{2}{ }^{2+}$, with small variations in the relative amounts of $\mathrm{UO}_{2} \mathrm{NO}_{3}{ }^{+}$or $\mathrm{UO}_{2}\left(\mathrm{NO}_{3}\right)_{2}$. As the spectra are largely determined by the amount of uranium present, only one $\mathrm{PC}$ is expected.

However, there are several indications that the GA-selected model is superior. For the first PC, the GA model has a lower prediction error for both cross-validation and the independent validation data sets than the full-range model. For higher PCs, the performance of the GAselected model degrades, indicating that those PCs are replicating noise that is uncorrelated with variation in uranium concentration. In comparison, significant prediction improvements are seen in the full-range model for PCs that do not represent a substantial portion of the signal variation $(\% \mathrm{X})$. This may represent an accidental correlation between noise and uranium concentration in the full data set. The use of the higher PCs for future predictions may be troublesome if the noise characteristics of the spectrophotometer change.

It is also worth noting that the GA analysis showed a number of different wavelength subsets that gave similar results. However, none of those subsets included the region of peak absorbance, $395-425 \mathrm{~nm}$. This is likely not due to nonlinearities at higher concentrations, as confirmed in literature [5] and by experience with the 1CU and 1EU colorimeters [6]. Instead, these wavelengths may have the bulk of the accidental correlation between noise and concentration, as described above for the full data set.

The final uranium model, compatible with the spectrophotometer control program, was generated using MVASRS. The smoothing/derivatization and PLS algorithms are similar, but not identical, to those in Solo. Therefore, the models built with MVASRS are not expected to be identical to those described above. The spectra were derivatized with a Guassian function with a 3-point window ${ }^{\dagger}$, and truncated to match the optimized spectral range from the GA analysis. An initial analysis suggested that the $0.9 \mathrm{~g} / \mathrm{L}$ data, which has the weakest absorbances, could be adversely affecting the model, so that data was transferred to the validation data set. Model results are presented in Table 2.

As with the scoping models described above, the best results are obtained with the 1-PC model. While the prediction error decreases with additional PCs, this improvement is obtained at the cost of an increased limit of quantitation (LOQ) as well as larger errors for the validation data. These trends suggest that the extra PCs over-fit the data and should be avoided.

\footnotetext{
* In Ref. 5, peak absorbance and uranium concentration were linearly correlated up to $30 \mathrm{~g} / \mathrm{L}$ for a $1 \mathrm{~cm}$ cuvette. For the 1EU colorimeter, nonlinearity was observed for $[\mathrm{U}]>25 \mathrm{~g} / \mathrm{L}$, but with a 1 inch path length (corresponding to $75 \mathrm{~g} / \mathrm{L}$ for a $1 \mathrm{~cm}$ path length).

${ }^{\dagger}$ Processing string: $2 d g 3$. The results are a very close match to the 15 point $/ 5^{\text {th }}$ order processing in Solo.
} 
Table 2. Uranium model results.

\begin{tabular}{|c|c|c|c|}
\hline PC & $\mathbf{1}$ & $\mathbf{2}$ & $\mathbf{3}$ \\
\hline $\mathbf{\% X}$ & 96.10 & 2.85 & 0.11 \\
\hline $\mathbf{\% Y}$ & 98.83 & 0.03 & 0.05 \\
\hline SEP (g/L) & 0.208 & 0.205 & 0.196 \\
\hline SEP (\% reading) & 1.3 & 1.4 & 1.3 \\
\hline LOQ (g/L) & 0.231 & 0.234 & 0.359 \\
\hline Bias (g/L) & 0.018 & 0.020 & 0.017 \\
\hline $\boldsymbol{r}^{\mathbf{2}}$ & 0.99986 & 0.99987 & 0.99988 \\
\hline Val. SEP (g/L) & 0.297 & 0.314 & 0.317 \\
\hline Val. SEP (\% reading) & 1.8 & 1.9 & 2.1 \\
\hline Val. LOQ (g/L) & 0.23 & 0.23 & 0.53 \\
\hline
\end{tabular}

(1) $\mathrm{SEP}=$ standard error of prediction (for calibration set, includes all data). (2) LOQ = limit of quantitation (10x the SEP for $[\mathrm{U}]=0 \mathrm{~g} / \mathrm{L})$.[7]

In Figure 3, the prediction errors are plotted against uranium concentration. The calibration data are plotted as diamonds, and the validation data are plotted as squares. There is a slight tendency to positive bias at low concentrations for the calibration data, although this is not repeated for the validation set. The regression coefficient $(r)$ for the calibration set is nearly equal to 1 , indicating a high degree of linearity. Also note that the $0.9 \mathrm{~g} / \mathrm{L}$ samples, moved to the validation set, are predicted accurately. This is consistent with the low LOQ obtained for both the calibration and validation sets.

Additionally, the average values for the three replicates of the cal04 sample were 23.83, 23.82, and $23.86 \mathrm{~g} / \mathrm{L}$. These results agree closely with each other (as well as with the reference value, $23.82 \mathrm{~g} / \mathrm{L}$ ) and suggest that there is little or no time dependence in the data set.

The 1-PC model was saved with the file name HCURNSK1.PLS in accordance with the naming conventions for the data acquisition program [1].

\subsubsection{Nitric Acid}

The minor spectral dependence on acid concentration could be safely ignored for uranium predictions, as attested by the use of one PC in that model. However, acid predictions depend on those minor spectral changes, and in this case the larger changes correlating with uranium must be ignored. This can be done by dividing the spectra by the uranium concentration.[1] Solutions with the same acidity but different uranium concentrations will then give the same absorption spectrum. In practice, it is easier to perform the normalizing on the predicted values rather than the spectra. Thus, in the calibration the spectra are fit to the product of nitrate and uranium concentrations for each sample.

\footnotetext{
* When the spectrophotometer is operated in the field, the spectrum is analyzed for uranium first. The result of the subsequent nitrate analysis is divided by the uranium value to get a prediction of true nitrate.
} 


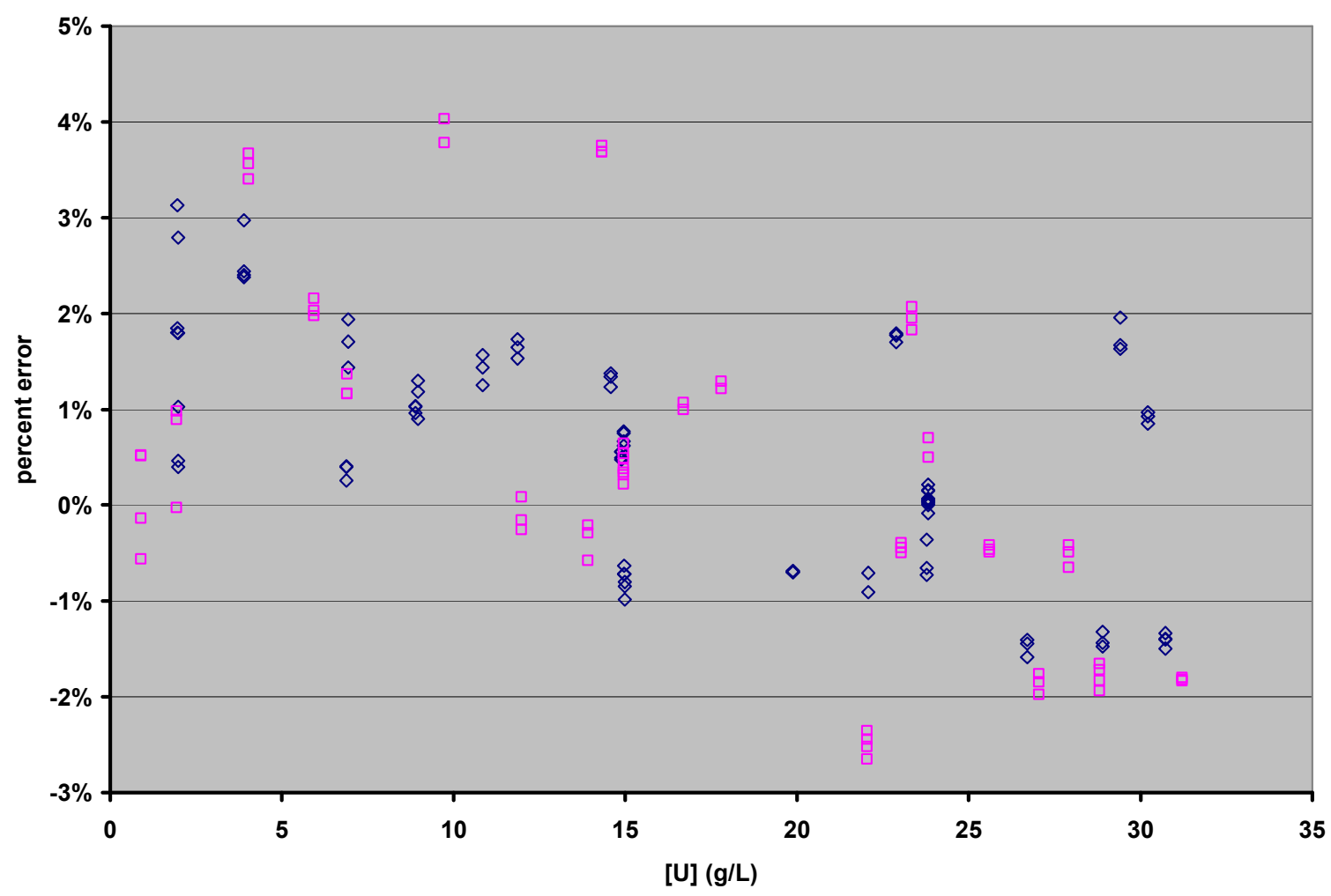

Figure 3. Prediction residuals for uranium model.

$(\diamond$ - calibration, $\square-$ validation $)$

As the nitrate prediction is more dependent on spectral shape, the choice of derivatization may be more critical than for uranium. Consequently, a wider range of derivatization options were considered in the initial GA analysis. GA parameters were the same as for the initial uranium scoping analysis, with the exception of allowing 3-PC models. The results are summarized in Table 3. Note that in this and subsequent tables, the results have been recorrected to reflect the nitrate values only, rather than the nitrate-uranium product.

Table 3. Derivatization analysis: nitrate model.

\begin{tabular}{|c|c|c|c|}
\hline Window & Poly. order & RMSECV (init.) (M) & RMSECV (final) (M) \\
\hline 5 & 3 & 1.1 & 0.47 \\
\hline 9 & 3 & 0.38 & 0.28 \\
\hline 9 & 5 & 1.2 & 0.36 \\
\hline 15 & 3 & 0.33 & 0.26 \\
\hline 15 & 5 & 0.51 & 0.28 \\
\hline 27 & 5 & 0.36 & 0.26 \\
\hline 51 & 5 & 0.56 & 0.37 \\
\hline
\end{tabular}


Less accurate observations are observed for the smallest and largest smoothing windows. Presumably, the smallest window does not adequately smooth the point-to-point noise in the spectrum, while the largest window smears out the variations that constitute the nitrate dependence. The lowest RMSECV between these extremes is for 15 or 27-point smoothing, with insignificant variation due to polynomial order. The 15 -point window, $5^{\text {th }}$ order polynomial was selected for subsequent work to match the choice for uranium analysis.

The next GA analysis was intended to select the wavelength range to be included in the final model. As with the uranium analysis, data was organized into 5-point blocks, and the GA was initiated with half of the available data points, with no restriction as to whether points would be added or subtracted for the final set. The results of the full-range and selectedrange models are compared in Table 4. The GA-selected model outperforms the full-range model, indicating that the exclusion of some wavelengths is helpful for the predictions.

Table 4. Nitrate model: GA comparison.

\begin{tabular}{|c|c|c|c|c|c|c|c|c|}
\hline & \multicolumn{4}{|c|}{ Full range } & \multicolumn{4}{|c|}{ GA-selected range } \\
\hline \# points & \multicolumn{4}{|c|}{208} & \multicolumn{4}{|c|}{85} \\
\hline$\lambda$ included (nm) & \multicolumn{4}{|c|}{$380-550$} & \multicolumn{4}{|c|}{$\begin{array}{l}388.3-391.6 ; 413.1-428.8 ; 433.7- \\
437.0 ; 441.9-449.3 ; 454.3 ; 457.6 \\
462.5-469.9 ; 479.0-486.3 ; 495.4- \\
498.7 ; 503.6-506.9 ; 511.8-515.1 ; \\
\quad 524.1-527.4 ; 540.5-543.7\end{array}$} \\
\hline $\mathbf{P C}$ & 1 & 2 & 3 & 4 & 1 & 2 & 3 & 4 \\
\hline$\% \mathrm{X}$ & 99.89 & 0.10 & 0.00 & 0.01 & 99.92 & 0.08 & 0.00 & 0.00 \\
\hline$\% \mathrm{Y}$ & 67.93 & 30.97 & 0.99 & 0.05 & 67.62 & 31.46 & 0.87 & 0.01 \\
\hline RMSECV (M) & 0.339 & 0.135 & 0.049 & 0.038 & 0.342 & 0.127 & 0.028 & 0.030 \\
\hline Val. RMSE (M) & 0.253 & 0.102 & 0.034 & 0.029 & 0.254 & 0.091 & 0.028 & 0.029 \\
\hline
\end{tabular}

Note that the third PC makes a substantial difference in accurately predicting acid concentration, but does so based on a comparatively small part of the overall signal. This pattern is consistent with the physical presence of three uranyl nitrate species, and with one of the species $\left(\mathrm{UO}_{2}\left(\mathrm{NO}_{3}\right)_{2}\right)$ having a small concentration (less than $2 \%$ [8]). The third PC may be more susceptible to noise fluctuations, which could adversely affect future measurements. It is encouraging that the validation data set is well predicted. However, because the calibration and validation data were taken at the same time, they are not fully independent. Thus the successful validation analysis does not fully confirm the stability of the model. For future analysis, the performance of a 3-PC model should be closely compared to laboratory results until it is shown that the model is rugged under long-term operation.

Note that a substantial part of the overall error for both the full- and GA-selected models comes from samples with $0.055 \mathrm{M}$ nitric acid. In both cases, prediction errors are as high as $+/-100 \%$ (evenly distributed around zero). Errors for $0.1 \mathrm{M}$ are low and consistent with errors observed for higher concentrations. This result indicates that the lower limit for the nitrate model should be $0.1 \mathrm{M}$. 
The final nitrate model was generated with MVASRS. Based on the scoping results described above, the $0.055 \mathrm{M}$ data were moved from the calibration to the validation data set, the data were truncated to match the GA-selected range, and the spectra were derivatized in the same way as for the uranium analysis. After an initial analysis, two additional spectra were observed to be outliers and were thus also moved to the validation set. Results of the analysis are shown in Table 5.

Table 5. Nitric acid model results.

\begin{tabular}{|c|c|c|c|c|}
\hline PC & $\mathbf{1}$ & $\mathbf{2}$ & $\mathbf{3}$ & $\mathbf{4}$ \\
\hline $\mathbf{\% X}$ & 97.08 & 1.87 & 0.16 & 0.07 \\
\hline \%Y & 45.89 & 44.96 & 6.65 & 0.46 \\
\hline SEP $^{\mathbf{1}}$ (M) & 0.317 & 0.119 & 0.017 & 0.018 \\
\hline SEP (\% reading) & 152 & 24 & 4.6 & 4.5 \\
\hline Bias & -0.057 & -0.062 & -0.002 & -0.003 \\
\hline $\boldsymbol{R}^{2}$ & 0.69901 & 0.99162 & 0.99938 & 0.99958 \\
\hline Val. SEP (M) $^{2}$ & $0.29 / 0.25$ & $0.10 / 0.09$ & $0.04 / 0.03$ & $0.04 / 0.03$ \\
\hline Val. SEP (\% reading) $^{\mathbf{3}}$ & 63 & 17.1 & 7.2 & 7.0 \\
\hline
\end{tabular}

(1) SEP = standard error of prediction. (2) Error with outlier and low-range calibration data / original validation set only. (3) Original validation set only.

The results are consistent with those from the scoping work. As can be seen in Figure 4, the errors for both data sets (diamonds: calibration; squares: validation) are evenly distributed around zero. No formal LOQ is reported for this analysis. LOQ is defined from the standard deviation of the analysis of blank samples. Since the nitrate analysis of uranyl nitrate solutions involves division by the uranium value, analysis of a blank would entail division by zero. Instead, the limit of quantitation of $0.1 \mathrm{M}$ is defined based on the observed calibration set results. Note that this lower limit is still adequate to cover the normal processing range for both Tank 15.4 (0.1-0.2 M) and Tank $17.5(0.3-0.35 \mathrm{M})$.

The 3-PC model was saved with the name HCNITSK1.PLS.

\subsection{CONCLUSIONS}

The model prediction uncertainties for both uranium and nitric acid are not consistent over the instrument range. Any statements about an overall uncertainty will probably mischaracterize the actual uncertainty at a particular concentration. For example, if the uranium uncertainty is estimated to be $0.6 \mathrm{~g} / \mathrm{L}$ (twice the uncertainty for the validation set), this infers that the uncertainty at $5 \mathrm{~g} / \mathrm{L}$ is $12 \%$. As shown in Figure 3, the observed uncertainty at that concentration is closer to $2-3 \%$ ( or $0.25 \mathrm{~g} / \mathrm{L}$ ). Therefore, the discussion of method uncertainty will include "percent-of-reading" uncertainties for the expected processing conditions in Tanks 15.4 and 17.5. The uncertainties given are twice the standard error of prediction. Bias for both uranium and nitrate is negligible. 


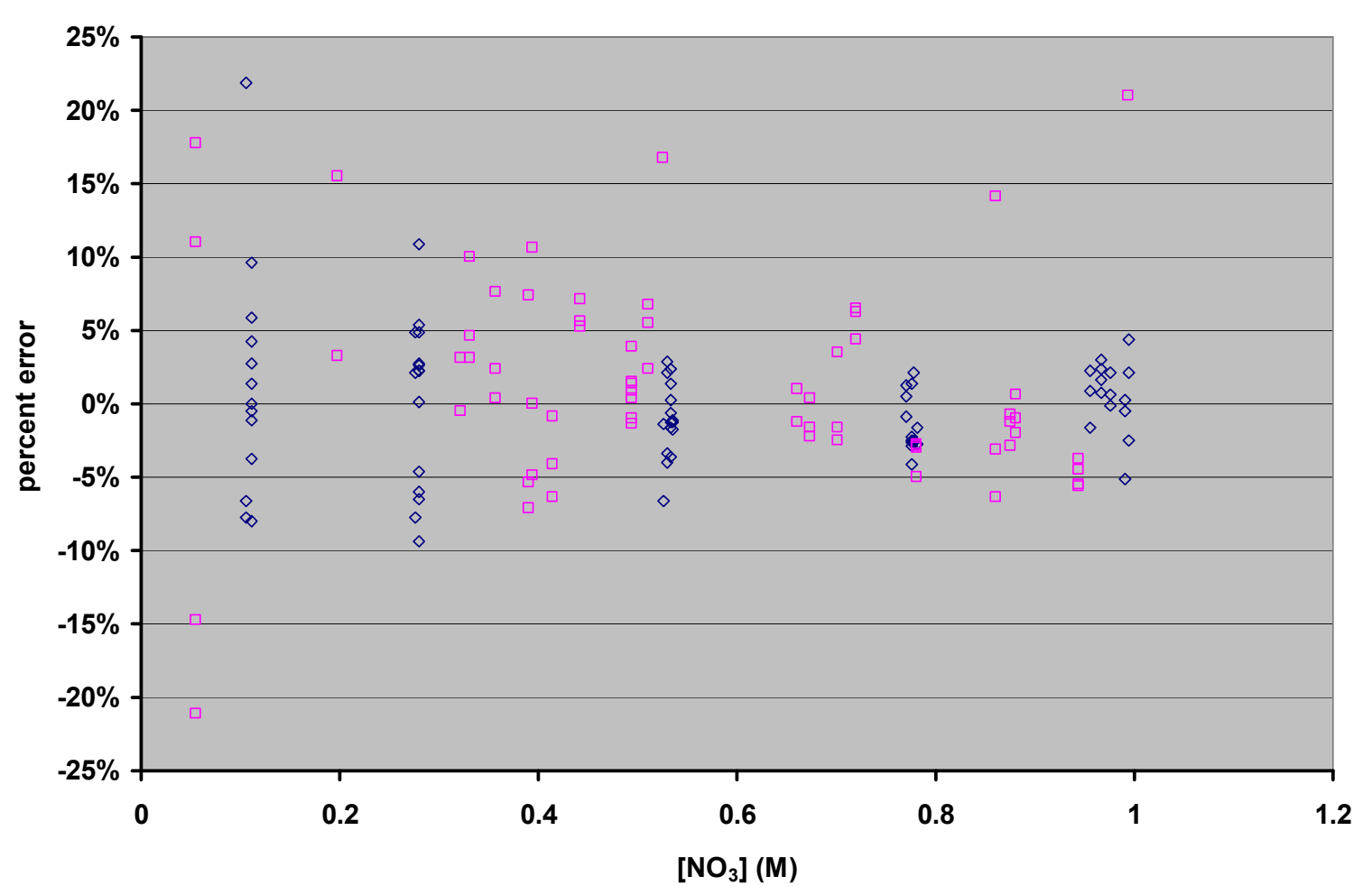

Figure 4. Prediction residuals for nitrate model.

$(\diamond$ - calibration, $\square-$ validation)

As discussed above, the method uncertainty must include both the model uncertainty and the uncertainty of the reference concentrations. The latter is based on the propagation of errors from the balances, densitometers, and methods used to make the calibration solutions. Example calculations are provided in Appendix 1. The model and reference uncertainties are assumed to be independent, and this are combined as the root-sum of squares. Results are summarized in Table 6.

It should be noted that the values in Table 6 may understate the true uncertainties, since they do not include measurements of truly independent samples (process solutions or poured calibration solutions), nor do they reflect measurements taken with the spectrophotometer at

Table 6. Uncertainty summary.

\begin{tabular}{|c|c|c|c|c|c|c|}
\hline & \multicolumn{3}{|c|}{ Uranium (g/L) } & \multicolumn{3}{c|}{ Nitric acid (M) } \\
\hline Model uncertainty $^{1}$ (overall) & \multicolumn{3}{|c|}{0.6} & \multicolumn{3}{c|}{0.09} \\
\hline Bias & \multicolumn{3}{|c|}{0.02} & \multicolumn{3}{c|}{-0.002} \\
\hline LOQ & \multicolumn{3}{|c|}{0.23} & \multicolumn{3}{c|}{} \\
\hline Uncertainties $_{\text {Tank 15.4 }}^{\mathbf{3}}$ & Model & Ref. & Method $^{2}$ & Model & Ref. & Method \\
\hline Tank 17.5 $^{4}$ & 0.68 & 0.64 & 0.93 & 0.024 & 0.03 & 0.04 \\
\hline & 0.46 & 0.35 & 0.58 & 0.042 & 0.07 & 0.08 \\
\hline
\end{tabular}

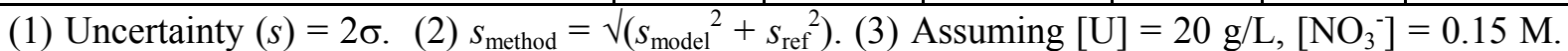

(4) Assuming $[\mathrm{U}]=11 \mathrm{~g} / \mathrm{L},\left[\mathrm{NO}_{3}^{-}\right]=0.35 \mathrm{M}$. 
a different time, when instrument noise may be different. As with any analytical instrument, spectrophotometer readings should be compared regularly against the results of other methods to guard against drift. These values also do not include any uncertainty associated with using the air-lift samplers. Because the samplers are operated in a sample-and-hold method, rather than allowing the solution to circulate freely, the uncertainty should be small compared to the method uncertainty, and is assumed negligible for the purposes of this discussion.

Converted to a percentage, the reading uncertainties $(s)$ for Tank 15.4 are estimated as $4.6 \%$ for uranium and $27 \%$ for nitric acid. For Tank 17.5 the corresponding values are $5.3 \%$ and $23 \%$. The uranium uncertainties are similar to those for the original model $(4 \%$ and $5 \%$, respectively. [1] Because the dependence of the absorbance on uranium concentration is so linear, it is reasonable that the prediction quality did not improve substantially. However, compared to the "interim" models currently in use, the new models are statistically rigorous and more likely to be rugged with long-term use. The comparatively large nitric acid uncertainties include large contributions from the uncertainty of the reference values (which can be traced to the $20 \%(s)$ uncertainty for the nitric acid stock solution concentration). Also, the relative concentration of the different uranyl nitrate species does not change substantially at these concentrations, and thus there is some spectral insensitivity that contributes to the model uncertainty. Nonetheless, these values are substantial improvements compared to the original models, for which the acid readings for these tanks were meaningless ( $200 \%$ and $500 \%$, respectively). The uncertainties are still small enough to allow the measurements to have value for process control.

\subsection{ACKNOWLEDGEMENTS}

Kathy White and Elaine Pearson (SRNL/AD) made and characterized the calibration solutions. Leigh Brown (SRNL/AD) coordinated solution transfer between SRNL and H Canyon. Ronnye Eubanks, Robert Dunlap, and Pamela Lott (H Canyon) provided engineering operations support.

\subsection{REFERENCES}

[1] R.J. Lascola, R.R. Livingston, M.A. Sanders, J.E. McCarty, and G.A. Cooper, "On Line Spectrophotometric Measurements of Uranium and Nitrate in H Canyon", WSRC-TR-2002-00334, Savannah River Technology Center, Aiken, SC (2002).

[2] R. Leardi, "Application of genetic algorithm - PLS for feature selection in spectral data sets", J. Chemometrics 14, 643-655 (2000).

[3] R. Leardi, "Genetic algorithms in chemometrics and chemistry - a review", $J$.

Chemometrics 15, 559-569 (2001).

[4] P.J. Gemperline, Practical Guide to Chemometrics, $2^{\text {nd }}$ Ed., P. Gemperline, ed., Taylor \& Francis, Boca Raton, FL, Chapter 4 (2006).

[5] J. Bürck, "Spectrophotometric Determination of Uranium and Nitric Acid by Applying Partial Least-Squares Regression to Uranium(VI) Absorption Spectra", Anal. Chim. Acta 254, 159-165 (1991). 
[6] R.J. Lascola, "Characterization of H Canyon Colorimeter Performance at Extended Uranium Concentrations", WSRC-STI-2007-00217, Savannah River National Laboratory, April, 2007.

[7] D.C. Harris, Quantitative Chemical Analysis, 3rd Ed., W.H. Freeman \& Co., New York (1991).

[8] C. Moulin, P. Decambox, P. Mauchien, D. Pouyat, and L. Couston, "Direct Uranium(VI) and Nitrate Determinations in Nuclear Reprocessing by Time-Resolved Laser-Induced Fluorescence", Anal. Chem. 68, 3204-3209 (1996). 


\section{APPENDIX 1}

The two sources of uncertainty for the uranium and nitric acid models are the concentrations of the standard solutions and the ability of the prediction models to reproduce the standard concentrations (i.e. root-mean-square error of prediction or cross-validation). The model errors are reported in the main text. This appendix shows the derivation of the standard concentration uncertainty from the uncertainties associated with the stock solution concentrations and their mixing.

Uncertainty, $s$, is reported as $\left(2 \sigma_{\text {random }}+\sigma_{\text {bias }}\right)$. [U] $=$ uranium, $[\mathrm{A}]=$ nitric acid.

Uranyl nitrate stock solution:

$[\mathrm{U}]_{\text {Ustock }}=437 \mathrm{~g} / \mathrm{L}, s_{[\mathrm{U}] \text { Ustock }}=1.64 \%$

(Analytical Laboratories; $\sigma_{\text {random }}=0.82 \%, \sigma_{\text {bias }}=$ negligible)

$[\mathrm{A}]_{\text {Ustock }}=0.24 \mathrm{M}, s_{[\mathrm{A}] \text { Ustock }}=6.0 \%$

(Analytical Laboratories; $\sigma_{\text {random }}=2.6 \%, \sigma_{\text {bias }}=0.8 \%$ )

$\rho_{\text {Ustock }}=1.6 \mathrm{~g} 1 / \mathrm{mL}, s_{\rho \text { Ustock }}=2 \%$

Nitric acid stock solution:

$[\mathrm{A}]_{\text {Astock }}=6.72 \mathrm{M}, s_{[\mathrm{A}] \text { Astock }}=20 \%$

$\left(\mathrm{SRNL}\right.$ measurement, $\left.\sigma_{\text {random }}=10 \%\right)$

$\rho_{\text {Astock }}=1.2 \mathrm{~g} / \mathrm{mL}, s_{\rho \text { Astock }}=2 \%$

All density $(\rho)$ measurements: $s_{\text {psolution }}=2 \%$

All individual mass (m) measurements: $s_{\mathrm{m}}=0.004 \mathrm{~g}$

Total standard solution mass is the sum of water, uranium, and nitric acid stock solution masses, i.e. $s_{\text {msolution }}=\left(3 \cdot .004^{2}\right)^{1 / 2}=0.007 \mathrm{~g}$

Assume that a "typical" standard solution has a total mass $\mathrm{m}_{\text {solution }}=30 \mathrm{~g}$, including a mass of uranyl nitrate stock solution $\mathrm{m}_{\text {Ustock }}=2 \mathrm{~g}$ and of nitric acid stock solution $\mathrm{m}_{\text {Astock }}=2.5 \mathrm{~g}$.

Expected concentrations for Tank 15.4: $[\mathrm{U}]=20 \mathrm{~g} / \mathrm{L},[\mathrm{A}]=0.15 \mathrm{M}$. For Tank 17.5: $[\mathrm{U}]=11$ $\mathrm{g} / \mathrm{L},[\mathrm{A}]=0.35 \mathrm{M}$.

Note that error propagation is calculated as follows. For addition or subtraction,

$$
x=p+q-r ; \quad s_{x}=\left(s_{x}^{2}+s_{q}^{2}+s_{r}^{2}\right)^{1 / 2} .
$$

For multiplication and division,

$$
x=p \cdot q / r ; f_{S_{x}}=s_{x} x=\left(f_{S^{2}}{ }_{x}+f s^{2}{ }_{q}+f s^{2}{ }_{r}\right)^{1 / 2} .
$$


Uncertainty, [U]:

$[\mathrm{U}]=\left(\mathrm{m}_{\text {Ustock }} \cdot[\mathrm{U}]_{\text {Ustock }} / \rho_{\text {Ustock }}\right) /\left(\mathrm{m}_{\text {solution }} / \rho_{\text {solution }}\right)$

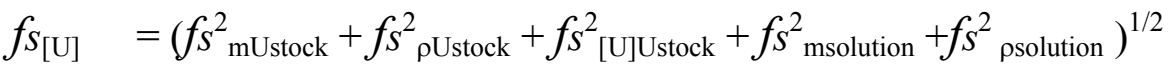

$=\left((0.004 \mathrm{~g} / 2 \mathrm{~g})^{2}+0.02^{2}+0.0164^{2}+(0.007 \mathrm{~g} / 30 \mathrm{~g})^{2}+0.02^{2}\right)^{1 / 2}$

$=0.032(=3.2 \%)$

Uncertainty, [A]:

$[\mathrm{A}]=\left(\mathrm{m}_{\text {Ustock }} \cdot[\mathrm{A}]_{\text {Ustock }} / \rho_{\text {Ustock }}+\mathrm{m}_{\text {Astock }} \cdot[\mathrm{A}]_{\text {Astock }} / \rho_{\text {Astock }}\right) /\left(\mathrm{m}_{\text {solution }} / \rho_{\text {solution }}\right)$

If $[\mathrm{A}]=\mathrm{A}_{\text {num }} / \mathrm{A}_{\text {denom, }}$ with

and

$$
\mathrm{A}_{\text {num }}=\mathrm{m}_{\text {Ustock }} \cdot[\mathrm{A}]_{\text {Ustock }} / \rho_{\text {Ustock }}+\mathrm{m}_{\text {Astock }} \cdot[\mathrm{A}]_{\text {Astock }} / \rho_{\text {Astock }}
$$

then

$$
\mathrm{A}_{\text {denom }}=\mathrm{m}_{\text {solution }} / \rho_{\text {solution }},
$$

where

$$
f_{S_{[\mathrm{A}]}}=\left(f_{s_{\text {Anum }}^{2}}+f_{s_{\text {Adenom }}^{2}}\right)^{1 / 2},
$$

$$
\begin{aligned}
& f s_{\text {Anum }}^{2}=1 / \mathrm{A}_{\text {num }}^{2} . \\
& \left(\left[\mathrm{m}_{\text {Ustock }} \cdot[\mathrm{A}]_{\text {Ustock }} / \rho_{\text {Ustock }}\right]^{2} \cdot\left(f_{s_{\text {mUstock }}}+f s^{2}{ }_{\text {pUstock }}+f s^{2}{ }_{\text {[U]Ustock }}\right)+\right. \\
& {\left[\mathrm{m}_{\text {Astock }} \cdot[\mathrm{A}]_{\text {Astock }} / \rho_{\text {Astock }}\right]^{2} \cdot\left(f_{s_{\text {mAstock }}}+f_{\left.s^{2}{ }_{\text {AAstock }}+f_{s^{2}}{ }_{\text {[U]Astock }}\right)}\right)} \\
& f_{\mathrm{s}^{2}}^{2} \text { Adenom }=f s_{\text {msolution }}^{2}+f s^{2} \text { psolution . }
\end{aligned}
$$

Thus,

$$
\begin{aligned}
& \mathrm{A}_{\text {num }}=(2 \mathrm{~g} \cdot 0.24 \mathrm{M} / 1.6 \mathrm{~g} / \mathrm{mL})+(2.5 \mathrm{~g} \cdot 6.72 \mathrm{M} / 1.2 \mathrm{~g} / \mathrm{mL})=14.3 \mathrm{M} \cdot \mathrm{mL} \\
& f_{S_{\text {Anum }}{ }^{2}=} 1 /(14.3 \mathrm{M} \cdot \mathrm{mL})^{2} \cdot\left((2 \mathrm{~g} \cdot 0.24 \mathrm{M} / 1.6 \mathrm{~g} / \mathrm{mL})^{2} \cdot\left((0.004 \mathrm{~g} / 2 \mathrm{~g})^{2}+0.02^{2}+0.06^{2}\right)+\right. \\
&\left.(2.5 \mathrm{~g} \cdot 6.72 \mathrm{M} / 1.2 \mathrm{~g} / \mathrm{mL})^{2} \cdot\left((0.004 \mathrm{~g} / 2.5 \mathrm{~g})^{2}+0.02^{2}+0.2^{2}\right)\right) \\
&= 4.89 \cdot 10^{-3} \cdot\left(3.60 \cdot 10^{-4}+7.92\right)=3.87 \cdot 10^{-2} \\
& f_{\mathrm{s}_{\text {Adenom }}}=(0.007 \mathrm{~g} / 30 \mathrm{~g})^{2}+0.02^{2}=4.00 \cdot 10^{-4} \\
& f_{S_{[\mathrm{A}]}=}\left(3.87 \cdot 10^{-2}+4.00 \cdot 10^{-4}\right)^{1 / 2}=0.198(=19.8 \%) .
\end{aligned}
$$

For specific tanks, the calibration standard uncertainties are thus:

Tank 15.4: $\quad[\mathrm{U}]=20 \mathrm{~g} / \mathrm{L}, s_{[\mathrm{U}]}=20 \mathrm{~g} / \mathrm{L} \cdot 0.032=0.64 \mathrm{~g} / \mathrm{L}$

$$
[\mathrm{A}]=0.15 \mathrm{M}, s_{[\mathrm{A}]}=0.15 \mathrm{M} \cdot 0.198=0.03 \mathrm{M}
$$

Tank 17.5: $\quad[\mathrm{U}]=11 \mathrm{~g} / \mathrm{L}, s_{[\mathrm{U}]}=11 \mathrm{~g} / \mathrm{L} \cdot 0.032=0.35 \mathrm{~g} / \mathrm{L}$,

$$
[\mathrm{A}]=0.35 \mathrm{M}, s_{[\mathrm{A}]}=0.35 \mathrm{M} \cdot 0.198=0.07 \mathrm{M} \text {. }
$$

